\title{
Characterization of a Sandwich PLGA-Gallic Acid-PLGA Coating on Mg Alloy ZK60 for Bioresorbable Coronary Artery Stents
}

\author{
Li-Han Lin ${ }^{1}$, Hung-Pang Lee ${ }^{2}$ and Ming-Long Yeh ${ }^{1,3, *(1)}$ \\ 1 Department of Biomedical Engineering, National Cheng Kung University, Tainan 701, Taiwan; \\ d09522010@ntu.edu.tw \\ 2 Biomedical Engineering, Dwight Look College of Engineering, Texas A\&M University, College Station, \\ TX 77843, USA; qer6322129@tamu.edu \\ 3 Medical Device Innovation Center, National Cheng Kung University, Tainan 701, Taiwan \\ * Correspondence: mlyeh@mail.ncku.edu.tw; Tel.: +886-6275-7575 (ext. 63429); Fax: +886-6234-3270
}

Received: 8 November 2020; Accepted: 2 December 2020; Published: 4 December 2020

\begin{abstract}
Absorbable magnesium stents have become alternatives for treating restenosis owing to their better mechanical properties than those of bioabsorbable polymer stents. However, without modification, magnesium alloys cannot provide the proper degradation rate required to match the vascular reform speed. Gallic acid is a phenolic acid with attractive biological functions, including anti-inflammation, promotion of endothelial cell proliferation, and inhibition of smooth muscle cell growth. Thus, in the present work, a small-molecule eluting coating is designed using a sandwich-like configuration with a gallic acid layer enclosed between poly (D,L-lactide-co-glycolide) layers. This coating was deposited on ZK60 substrate, a magnesium alloy that is used to fabricate bioresorbable coronary artery stents. Electrochemical analysis showed that the corrosion rate of the specimen was 2000 times lower than that of the bare counterpart. The released gallic acid molecules from sandwich coating inhibit oxidation by capturing free radicals, selectively promote the proliferation of endothelial cells, and inhibit smooth muscle cell growth. In a cell migration assay, sandwich coating delayed wound closure in smooth muscle cells. The sandwich coating not only improved the corrosion resistance but also promoted endothelialization, and it thus has great potential for the development of functional vascular stents that prevent late-stent restenosis.
\end{abstract}

Keywords: magnesium alloy; cardiovascular stents; callic acid; dip coating; endothelialization; anticorrosion

\section{Introduction}

According to reports from the Global Health Organization in 2016, cardiovascular diseases (CVDs), the prevalence of which increased by $15 \%$ in the past decade, are the leading cause of death (44\%) among non-communicable diseases [1]. In clinical settings, a percutaneous coronary intervention (PCI) combined with balloon angioplasty and stent implantation is the gold standard for treating stenotic arteries. Currently, dual antiplatelet therapy is suggested for at least 12 months to alleviate mural thrombosis caused by PCI [2]. The traditional materials used in cardiovascular stents are $316 \mathrm{~L}$ stainless steels, cobalt-chromium alloys, and nickel-titanium alloys [3]. However, the permanent installation of devices inside the human body causes a chronic inflammatory local reaction and long-term endothelial dysfunction [4]. Biodegradable magnesium (Mg) and its alloys are ideal candidates for stent platforms because they have less neointimal formation and provide long-term inhibition of the growth of smooth muscle cells (SMCs), unlike stainless steel [5,6]. The Mg alloys also have twice the tensile strength of 
unmodified biodegradable poly-L-lactide (PLLA), which leads to flexible stenting deployment and better radial force [7-9].

To properly use a magnesium alloy as a biodegradable stent platform for physiological applications, the corrosion rate must be controlled. To date, the surfaces of degradable magnesium alloys have been modified in several ways, such as alkaline heat treatment (AHT), the sol-gel process, chemical conversion, and micro-arc oxidation (MAO) $[10,11]$. Although ceramic MAO processing may provide a consolidated surface [12-14] for clinical applications, a prior study showed that this process did not improve corrosion resistance after three months [15]. In contrast, a sol-gel coating can greatly improve the corrosion resistance with chemical modifications [16]. Polymetric processes create a physical barrier [17] that enhances the corrosion resistance of Mg-stents, and the barrier also serves as an absorbable drug-loading system [18,19]. A polymer coating of a specific thickness can prevent complete degradation of $\mathrm{Mg}$ alloys for periods of 1 to 12 months [20].

Phenolic molecules, such as gallic acids (GA), exert and induce specific levels of selective viability in human endothelial cells (ECs) and SMCs [21-24]. Furthermore, these extracted molecules have anti-oxidation characteristics that inhibit inflammation. Since cellular antioxidants prevent the formation of oxidized low-density lipoprotein (LDL) and antiplatelet activation, this is a remarkable method by which to treat atherosclerosis [25]. Although several articles have indicated that the phenolic conversion coating on a Mg-alloy is non-toxic and anti-corrosive, chemical conversion may compromise stent integrity through the phenolic-Mg conversion process [26-29].

$\mathrm{Mg}$-Zn alloys are well-known for their good corrosion resistance and physiological safety [30]. The ZK60 Mg-6Zn-0.5Zr alloy has been used to make vascular stents due to its better biocompatibility than those of other Mg alloys [31]. In addition, ZK60 has a high tensile strength (315 MPa) that prolongs the radial force of $\mathrm{Mg}$ stents. Nevertheless, the rapid degradation rate of bare ZK60 represents a shortcoming of the alloy for its use to fabricate bioresorbable coronary artery stents [15]. In this paper, a coating comprising of GA sandwiched between two layers of Poly (D,L-lactide-co-glycolide) (PLGA), a novel sandwich coating, on Mg alloy ZK60 concept was proposed. It can serve not only as a protective barrier that increases corrosion resistance but also as a reservoir for controlling GA release. The surface properties of coated-Mg stent and corrosion behavior of a $\mathrm{Mg}$ alloy were determined. Furthermore, cell viability and cell migration tests were performed to investigate the cell regulation of released GA in endothelialization as well as the effects on the growth of smooth muscle cells.

\section{Materials and Methods}

\subsection{Materials and Specimen Preparation}

In this study, extruded commercial ZK60 alloy bars (Zn 5.48 wt.\%, Zr 0.42 wt.\% and balance Mg) comprised the starting material for the substrate [32]. PLGA in molar ratio of 85/15 and GA with purity above $97.5 \%$ were purchased from Sigma-Aldrich (St. Louis, MO, USA; Figure 1a). ZK60 disks cut from the bars were reduced to $12 \mathrm{~mm}$ in diameter and $5 \mathrm{~mm}$ in thickness (Figure 1c). These specimens were ground with silicone carbide sandpaper (150-5000 mesh) and polished. Before being dried in a stream of air, all specimens were rinsed ultrasonically with acetone, ethanol, and distilled water for $5 \mathrm{~min}$, respectively. Mg-stent was machined by an INTAI Technology and CHONG HUAI laser (Taichung, Taiwan) for further evaluation.

\subsection{Sandwich Coating Films Preparation}

Mirror-polished ZK60 specimens were soaked in an alkaline solution composed of $20 \mathrm{wt} . \% \mathrm{NaOH}$. The solution was stirred at $240 \mathrm{rpm}$ and then heated for $90 \mathrm{~min}$ at $60^{\circ} \mathrm{C}$ to equilibrate the specimens. After $90 \mathrm{~min}$, the specimens were drawn out of the alkaline solution and rinsed with deionized water. The rinsed specimens were incubated at $80^{\circ} \mathrm{C}$ for $30 \mathrm{~min}$ until they were dried. Subsequently, heat treatment at $120^{\circ} \mathrm{C}$ for another $30 \mathrm{~min}$ was conducted to stabilize the oxide film. To fabricate the sol-gel PLGA coating layer, PLGA was dissolved at a concentration of $4 \mathrm{wt} . \%$ in $10 \mathrm{~mL}$ of chloroform. 
The PLGA film thickness depended on the drawing speed of $3 \mathrm{~mm} / \mathrm{s}$, and the film was dried in a stream of air to form a uniform dip-coating surface. Subsequently, different coating layers were prepared with or without GA solution. The samples were dipped into GA solution at a concentration of $1 \mathrm{wt} . \%$ and $10 \mathrm{~mL}$ acetone. Finally, the samples were ultrasonically rinsed with ethanol and air-dried. The coating steps were conducted on the Mg-stent for surface morphology observation.

\subsection{Characterization of the Surface, the Cross-Section Structure, and the Elements Content}

The crystallinity of ZK60 was analyzed using thin film X-ray diffraction (TF-XRD Bruker D8 Discover, Brucker, Karlsruhe, Germany) with $\mathrm{Cu}-\mathrm{K} \alpha$ radiation. Diffraction patterns were acquired at $2 \theta$ values of $20-80^{\circ}$. The surface morphology and element distributions of the coating films were studied by scanning electron microscopy (SEM JSM-6700F, JEOL, Tokyo, Japan) under $10 \mathrm{kV}$ acceleration voltage and energy dispersive spectrometry (EDS JSM-6700F, JEOL, Tokyo, Japan) under $0.2 \mathrm{keV}$ acquisition energy, respectively. The structures of the films were recorded with a Fourier transform-infrared (FT-IR) spectrophotometer (FTIR-4600, Jasco, Tokyo, Japan) at a transmitter ratio (T\%) and infra spectra resolution of $4 \mathrm{~cm}^{-1}$. The spectra were collected in the range of $600-4000 \mathrm{~cm}^{-1}$.

\subsection{Electrochemical Corrosion and Hydrogen Evolution Tests}

The electrochemical and hydrogen evolution tests were performed in revised simulated body fluid (r-SBF) solution (per liter, $0.072 \mathrm{~g}$ of $\mathrm{NaSO}_{4}, 0.182 \mathrm{~g}$ of $\mathrm{K}_{2} \mathrm{HPO}_{4}, 0.225 \mathrm{~g}$ of $\mathrm{KCl}, 0.310 \mathrm{~g}$ of $\mathrm{MgCl}_{2} 6 \mathrm{H}_{2} \mathrm{O}, 0.736 \mathrm{~g}$ of $\mathrm{NaHCO}_{3}, 0.923 \mathrm{~g}$ of $\mathrm{CaCl}_{2}, 2.036 \mathrm{~g} \mathrm{Na} \mathrm{CO}_{3}, 5.403 \mathrm{~g}$ of $\mathrm{NaCl}$, and $11.928 \mathrm{~g}$ of 4-(2-hydroxyethyl)-1-piperazineethanesulfonic avid (HEPES) dissolved in deionized water), respectively. In the electrochemical corrosion tests, a PARSTAT 2273 electrochemistry workstation (PARSTAT 2273, AMETEK, Berwyn, PA, USA) was operated at a scanning rate of $1 \mathrm{mV} \mathrm{s}^{-1}$ at $-2.0 \mathrm{~V}$ to $1.0 \mathrm{~V}$ with a step height of $2.5 \mathrm{mV}$ [12]. A reference saturated calomel electrode (SCE $\mathrm{KCl}$ ) combined with a conventional three-electrode electrode cell and a platinum plate was used for the electrochemical analysis. The area of the working electrode exposed to the electrolyte was controlled by a polylactic acid (PLA) holder to within $1 \mathrm{~cm}^{2}$. Each sample was tested for once and immersed in r-SBF solution at least three hours [12]. In hydrogen evolution test, all samples $(n=3)$ were freshly prepared and then placed in the r-SBF solution for $48 \mathrm{~h}$ at a $\mathrm{pH}$ of 7.4 and a temperature of $37^{\circ} \mathrm{C}$. The equipment then recorded the total volume of the hydrogen released from the magnesium alloys [32].

\subsection{Cytocompatibility Evaluation}

The cytocompatibility tests examined cytotoxicity, cell proliferation, and migration. A human umbilical vein cell line (EA. hy926) and a rat aortic smooth muscle cell line (RASMC) were provided by Wen-Tai Chiu (National Cheng Kung University, Tainan, Taiwan). The growth behaviors of the EA. hy926 and RASMC represented the cardiovascular ECs and SMCs, respectively. Before cell culturing, the sterile samples were immersed in free fetal bovine serum Dulbecco's Modified Eagle Medium (FBS DMEM) (approximately $1.25 \mathrm{~cm}^{2} / \mathrm{mL}$ in DMEM) for 24-h extraction. The resulting filtered (0.2 $\mu \mathrm{m}$ filter) medium was then diluted to a $15 \mathrm{~mL}$ volume. The cells were seeded separately at a density of 4000 cells/well in 96-well plates. The 90\% DMEM with 10\% dimethyl sulfoxide (DMSO) was used as the positive control, and 90\% DMEM with 10\% FBS was used as the negative control. The culture medium was replaced with $90 \%$ extracted medium with $10 \%$ FBS overnight. Before collection of the optical density (OD) values at $450 \mathrm{~nm}$, cell counting kit-8 (CCK8) solution was added into each well and the mixture was incubated for $2 \mathrm{~h}$. Briefly, the cell proliferation was recorded on days 1, 4, and 7 . Three replications were conducted and then the results were calculated using Equation (1) below.

Relative growth rate $\%=[($ OD test - OD positive $) /($ OD negative - OD positive $)] \times 100 \%$ 


\subsection{Hemolysis Tests}

The hemolysis tests were performed according to the ISO 10993-4 standard for biomaterials [33]. Sodium citrate ( $4 \mathrm{wt} . \%)$ to the fresh blood samples in the ratio of 1:9 was taken $30 \mathrm{~min}$ before the tests. All specimens were immersed in centrifuge tubes containing $10 \mathrm{~mL}$ of normal saline and incubated for $30 \mathrm{~min}$ at $37^{\circ} \mathrm{C}$. Deionized water was used as the positive control, and normal saline was used as the negative control. After $30 \mathrm{~min}$ of incubating, $0.2 \mathrm{~mL}$ of the diluted blood, prepared with normal saline at a volume ratio of 4:5, was added into the centrifuge tubes, and all the tubes were incubated for $60 \mathrm{~min}$ at $37^{\circ} \mathrm{C}$. After $60 \mathrm{~min}$, the tubes were centrifuged for $5 \mathrm{~min}$ at $2500 \mathrm{rpm}$, and the supernatant was collected and carefully transferred to a 96 -well plate for spectroscopic measurement. The hemolysis data, read by ELISA, were calculated using Equation (2) below and were based on the average of three replications:

$$
\text { Hemolysis } \%=[(\mathrm{OD} \text { test }-\mathrm{OD} \text { negative }) /(\mathrm{OD} \text { positive }-\mathrm{OD} \text { negative })] \times 100 \%
$$

\begin{tabular}{|c|c|c|}
\hline \multicolumn{3}{|c|}{ ZK60 Composition (wt\%) } \\
\hline $\mathrm{Mg}$ & $\mathrm{Zn}$ & $\mathrm{Zr}$ \\
\hline Balance & 5.48 & 0.42 \\
\hline
\end{tabular}

(a)

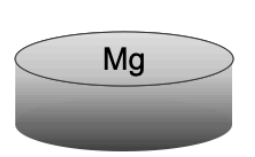

\section{Substrate}

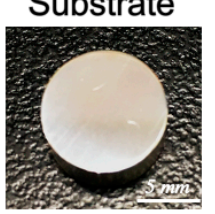

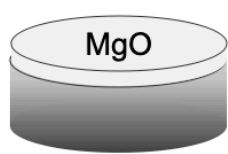

Oxide layer

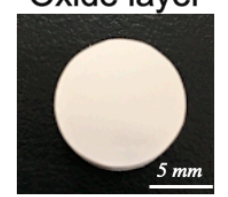

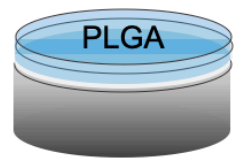
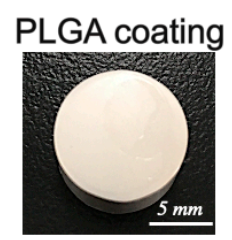
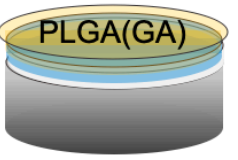

Sandwich coating

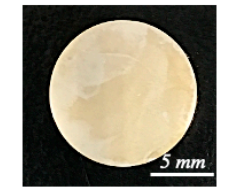

(b)

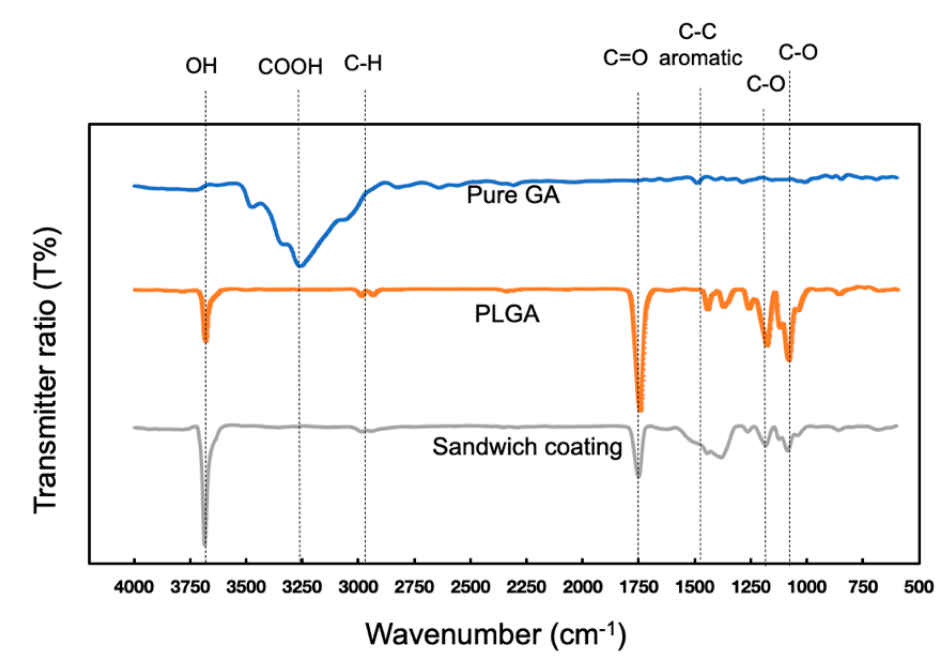

(c)

Figure 1. Composition of ZK60 (a) [34], the steps in the dip-coating procedure (b), and FT-IR spectra of GA, PLGA, and the sandwich coating (c). 


\subsection{Free Radical Activity Tests}

The free radical activity tests, measured diphenyl-2-picrylhydrazyl (DPPH), were performed according to application on bleached teeth and several antioxidant tests on magnesium alloys [34]. The DPPH powder was diluted in $0.2 \mathrm{mmol} / \mathrm{mL}$ DPPH solution with $70 \%$ ethanol. All specimens were immersed in $2 \mathrm{~mL}$ of DPPH solution and incubated at $37^{\circ} \mathrm{C}$ for $1 \mathrm{~h}$ in the dark. Similarly, DPPH solution was used as the control group. Then the absorbance of DPPH data, read by microplate reader, were calculated using Equation (3) below based on the average of three replications:

$$
\text { Inhibition } \%=[(\mathrm{OD} \text { control }-\mathrm{OD} \text { test }) / \mathrm{OD} \text { control }] \times 100 \%
$$

\subsection{Statistical Analysis}

In this study, all quantitative results are expressed as standard deviation (SD) unless indicated. Each assay was performed in at least three replicated tests, as described above. Measured experimental results from GraphPad Prism software (Prism 9.0, GraphPad, San Diego, CA, USA) were analyzed by a non-parametric test (Kruskal-Wallis Test) combined with Uncorrected Dunn's multiple comparisons test (each comparison stands alone), and a $p$-value $<0.05$ was considered significant.

\section{Results}

\subsection{Modification of the ZK60 Surface}

An as-extruded ZK60 disk scanned by XRD indicated three peaks at $32.2^{\circ}, 34.5^{\circ}$, and $36.8^{\circ}$, corresponding to $\mathrm{Mg}$ in Appendix A (Figure A1). As-extruded ZK60 cut disks were modified with AHT to develop a layer of magnesium hydroxide as Equation (4) below. The $\mathrm{Mg}(\mathrm{OH})_{2}$ layer was then treated at high temperature to form a rough $\mathrm{MgO}$ layer as Equation (5) following by the PLGA dip coating. These chemical reactions produced a less-active ZK60 surface and a compact void-free oxide for the dip-coating process. The void-free structure prevented inner bulk erosion on the polymer layer and external pitting corrosion on the highly active magnesium alloy. In comparison to the bare $\mathrm{ZK} 60$, the $\mathrm{MgO}$ coating had higher corrosion resistance to delay magnesium ions from bursting out in Appendix A (Figure A2). The sandwich coating steps were schematized and are depicted in order in Figure 1b. As illustrated in that figure, the bare ZK60 substrate was first treated with AHT and then coated with sandwich coating layers. Since hydrophilic GA was unable to dissolve in the oil phase, the hydrophobic PLGA was able to remain compact in the sandwich layer coating process.

The FT-IR analysis confirmed the encapsulation of GA in the polymer sandwich layers (Figure 1c). The wavenumbers of the functional group in GA were sourced from a published FT-IR article [35]. The presence of the benzene signal at $1482 \mathrm{~cm}^{-1}$ allowed a decisive characterization of the phenolic GA compound even though PLGA and GA shared several similar functional groups. The GA group had benzene vibration peaks at $1482 \mathrm{~cm}^{-1}$, and PLGA did not, while the interference of $C=O\left(1750 \mathrm{~cm}^{-1}\right)$ and $\mathrm{C}-\mathrm{O}\left(1250-1100 \mathrm{~cm}^{-1}\right)$ vibration peaks caused a broad benzene peak of the sandwich coating from $1600 \mathrm{~cm}^{-1}$ to $1300 \mathrm{~cm}^{-1}$. Also, the O-H peaks, representing tri-hydroxyl groups at $3683 \mathrm{~cm}^{-1}$, provided substantial evidence that the sandwich coating immobilized the GA in the sandwich structure.

$$
\begin{gathered}
\mathrm{Mg}^{2+}(a q)+2 \mathrm{OH}^{-}(a q) \rightleftharpoons \mathrm{Mg}(\mathrm{OH})_{2}(s) \\
\mathrm{Mg}(\mathrm{OH})_{2}(s) \stackrel{\Delta}{\rightarrow} \mathrm{MgO}(s)+\mathrm{H}_{2} \mathrm{O}(g) \uparrow
\end{gathered}
$$

\subsection{Effects of PLGA Dip-Coating and Phenolic Layer on the Coating Morphology}

The SEM images of the sandwich coating showed that the AHT-modified ZK60 surface became more uniform after a series of dip-coating processes (Figure 2). Initially, the morphology of the MgO after AHT was rough and coarse. After the PLGA dip-coating, a non-homogeneous microstructure formed on the $\mathrm{MgO}$ surface. After the second PLGA dip-coating, the top PLGA film layer smoothed 
the rough GA layer in the form of a sandwiched-layer structure. In addition, the SEM images indicated that PLGA and sandwich coatings had film thicknesses of $1.1 \pm 0.4 \mu \mathrm{m}$ and $2.1 \pm 0.3 \mu \mathrm{m}$, respectively, in the cross-section view. The thickness of the coating's cross-sections was proportionate with the number of PLGA layers.
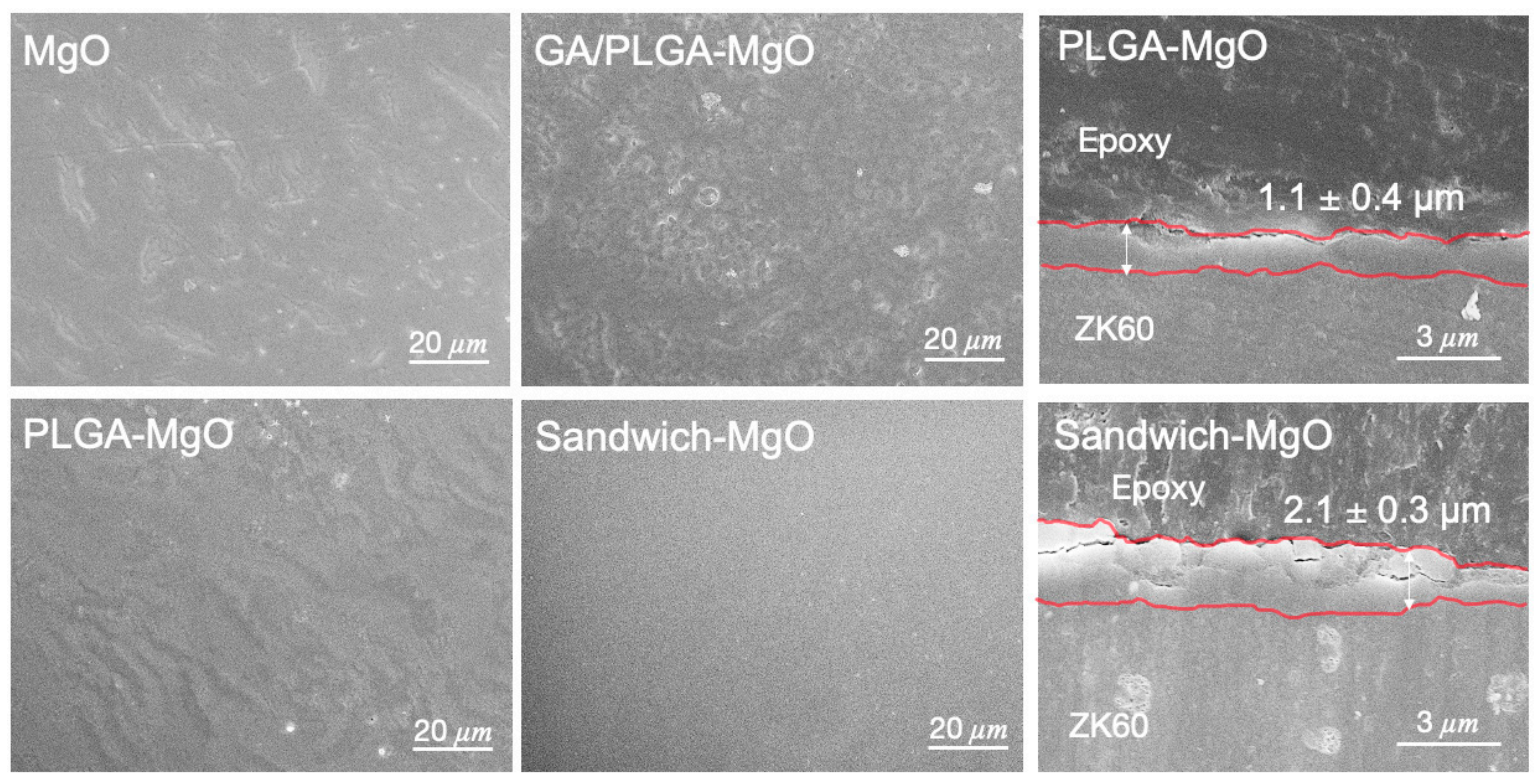

Figure 2. SEM images of the coating steps: $\mathrm{MgO}$, PLGA-MgO, GA/PLGA-MgO, and Sandwich-MgO, the cross-section images of PLGA-MgO $(1.1 \pm 0.4 \mu \mathrm{m})$ and Sandwich-MgO $(2.1 \pm 0.3 \mu \mathrm{m})$.

EDS detection confirmed that the sandwich layers covered the bare ZK60, as shown in the elemental distribution in Figure 3a. In the $\mathrm{MgO}$ layer, magnesium and oxygen accounted for 36.9\% and $63.1 \%$, respectively, while in the final sandwich coating film, $\mathrm{Mg}$ and oxygen $(\mathrm{O})$ accounted for $7.2 \%$ and $23.4 \%$, respectively, with the balance being carbon $(\mathrm{C})$. The decreases in the contents of $\mathrm{Mg}$ and $\mathrm{O}$ with the layers verified that the PLGA coating protected the $\mathrm{MgO}$ surface. Furthermore, the rising $\mathrm{C}$ contents of GA and PLGA indicated bare Mg substrate was covered by the coating. Next, an EDS line scan was applied to analyze the elemental changes in the sandwich coating (Figure 3b,c). Based on the changes in the ratios of the element weights, the highest content of $\mathrm{Mg}$ was in the ZK60 region. Due to the rich oxygen contents of $\mathrm{MgO}, \mathrm{GA}$, and PLGA, the increasing $\mathrm{O}$ and declining $\mathrm{Mg}$ contents indicated the $\mathrm{MgO}$ layer and sandwich coating. Furthermore, the rising carbon signal originated from the mounting epoxy resin. The film thickness observed in the SEM images was consistent with the EDS analysis measured from the first $\mathrm{Mg}-\mathrm{O}$ crossing point to the second $\mathrm{Mg}-\mathrm{C}$ crossing point in the PLGA and sandwich coating films.

To evaluate the dip-coating effect on the ZK60 stent platform, the coating steps mentioned above were repeated on the ZK60 stent prototype. Although the ZK60 stent developed irregular corrosive struts without the coating, the coated Mg-stent retained its stent integrity, and a uniform polymer coating formed on its surface (Figure 4 ). 


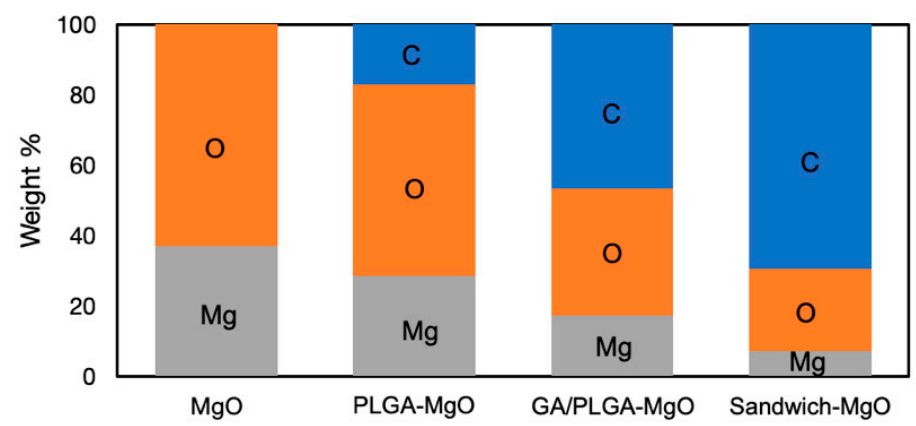

(a)

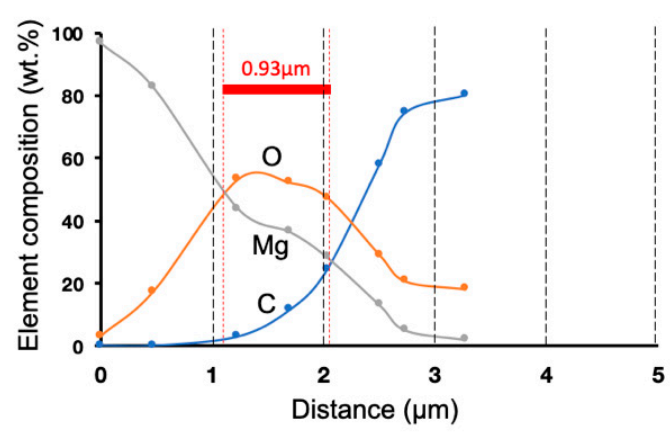

(b)

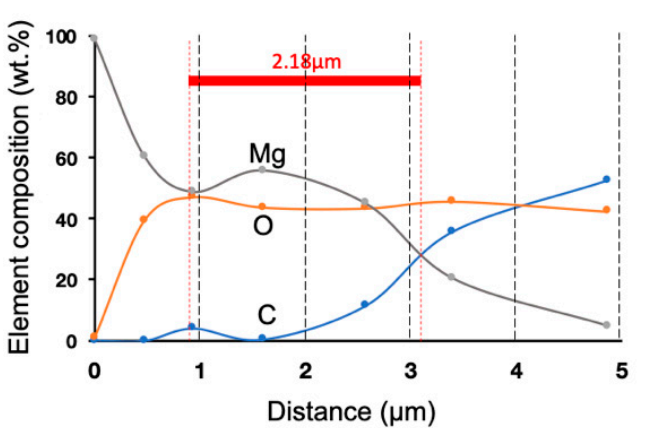

(c)

Figure 3. EDS composition analysis of (a) different layers and cross-sections of the (b) PLGA, and (c) sandwich coating films.
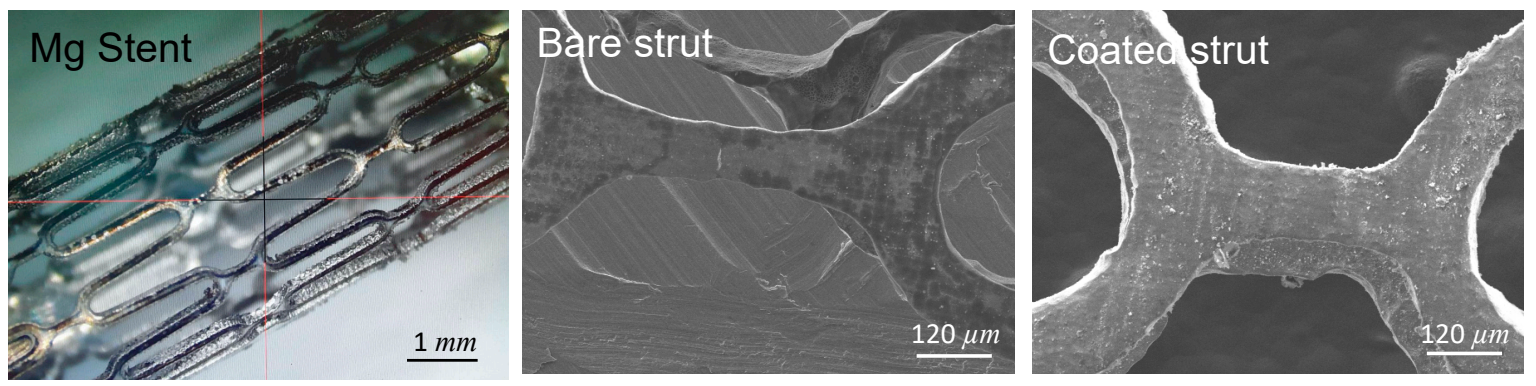

Figure 4. Mg-stent prototype, and the SEM images of the bare strut and sandwich-coated strut.

\subsection{Anti-Corrosion Behavior}

The hydrogen evolution was recorded for $48 \mathrm{~h}$. The results indicated the highest $\mathrm{H}_{2}$ volume for the untreated ZK60, and the lowest, for sandwich coating (Figure 5a). The electrochemical analysis showed results comparable to those for hydrogen release. The lowest corrosion density of the sandwich coating, acquired from the potentiodynamic polarization curves, suggested that the sandwich coating improved the corrosion resistance (Figure 5b). The unmodified ZK60 had the lowest corrosion potential, $-1.6 \mathrm{~V}$, and the highest corrosion current density, $20.51 \mu \mathrm{A} / \mathrm{cm}^{2}$, which corresponded to the $\mathrm{H}_{2}$ release, indicating that the bare surfaces did suffer a severe corrosion attack in the physiological environment (Table 1). Furthermore, the PLGA had a higher corrosion potential, $-0.4 \mathrm{~V}$, and a lower corrosion current density, $1.79 \mu \mathrm{A} / \mathrm{cm}^{2}$, and the sandwich coating also exhibited a slightly increased corrosion potential of $-0.2 \mathrm{~V}$ and a decreased corrosion current density of $0.01 \mu \mathrm{A} / \mathrm{cm}^{2}$ than those of the bare ZK60. These findings suggested a significant difference between PLGA and sandwich coating in terms of electrochemical performance. This sandwich structure provided a better corrosion resistance. 


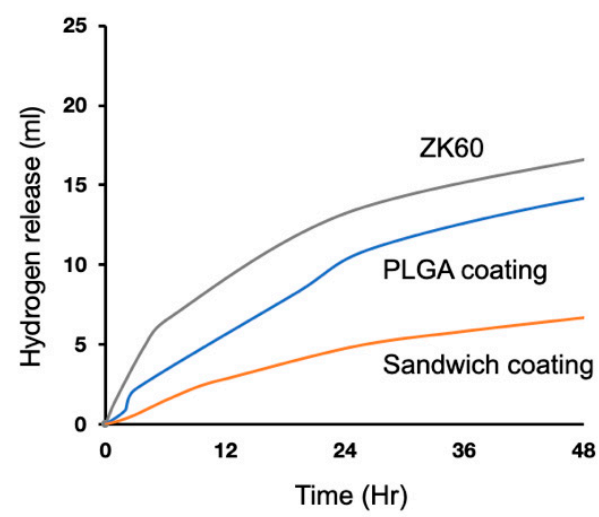

(a)

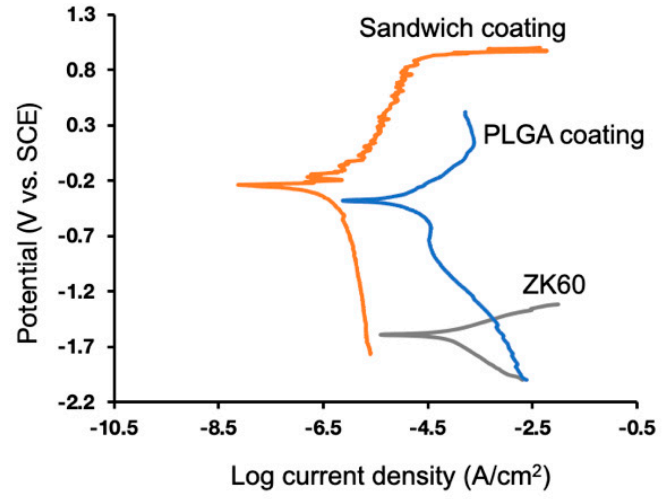

(b)

Figure 5. Corrosion resistance tests: (a) Hydrogen evolution curves of ZK60, PLGA coating and sandwich coating and (b) Potentiodynamic polarization curves of ZK60, PLGA coating, and sandwich coating in SBF solution.

Table 1. Fitting results for the potentiodynamic polarization curves related to Figure $5 \mathrm{~b}$. The inhibition efficiency was calculated as " $\eta \%=[1$ - (Icorr. sample/Icorr. Bare ZK60) $] \times 100 \%$ ".

\begin{tabular}{ccccc}
\hline \multirow{2}{*}{ Specimen } & \multicolumn{4}{c}{ Polarization Curves } \\
\cline { 2 - 5 } & Ecorr $(\mathbf{V})$ & $\log$ Icorr $\left(\boldsymbol{\mu} \mathbf{A} / \mathbf{c m}^{\mathbf{2}}\right)$ & Icorr $\left(\boldsymbol{\mu} \mathbf{A} / \mathbf{c m}^{\mathbf{2}}\right)$ & $\eta \mathbf{~ ( \% )}$ \\
\hline Bare ZK60 & -1.59 & -4.69 & 20.51 & 0.00 \\
PLGA coating & -0.40 & -5.75 & 1.79 & 91.27 \\
Sandwich coating & -0.24 & -8.00 & 0.01 & 99.95 \\
\hline
\end{tabular}

\subsection{Effect of Phenolic Molecules on ECs and SMCs in TERMS of Cell Viability and Hemolysis}

The sandwich coating layers promoted EC proliferation but inhibited the growth of SMCs (Figure 6). Changes in GA gradient resulted in varying EC vitality, demonstrating the relationship between EC tolerance and GA toxicity in Appendix A (Figure A3). The outcome demonstrated that the GA 1 wt.\% group had better viability than did the other two groups, while the highly-concentrated GA suggested that direct over-exposure could cause apoptosis due to the high antioxidant activity. After comparison to different groups, including bare (ZK60), PLGA and sandwich coating, at 1, 4, and 7 days, sandwich coating showed no toxicity to ECs (Figure 6c).

Based on the cell viability of the ECs and SMCs, there were two notable points: the non-toxic growth rate of sandwich coating towards ECs, and the selective suppression of SMCs (Figure 6a,b). In comparison to bare ZK60, the PLGA and sandwich coatings exhibited significant viability in ECs. The SMCs exhibited proliferation in the PLGA group, while sandwich coating only had $90 \%$ viability after four days. Even though the proliferation of the ECs declined on Day 4, the decline could have been due to the high content of GA released in a static environment. The efficiency of GA, while not significant in the SMCs, was moderate in strength. These results indicated that the ECs had a robust proliferation growth rate of $150 \%$ compared to the SMC group, and sandwich coating inhibited SMC over-growth. None of the groups exhibited toxicity in the comparison tests; thus, the four-day test was sufficient to observe the growth trend, while a seven-day test would have soon reached $100 \%$ coverage and lost the trend in our relative growth study.

Sandwich coating presented a hemolysis ratio below $5 \%$, corresponding to the clinical bio-safety standard (Figure $6 \mathrm{~d}$ ). The bare ZK60 had a high hemolysis ratio of more than $43 \%$, while both sandwich coating and PLGA showed lower hemolysis rates of $2.1 \%$ and $3.8 \%$, respectively. Overall, the sandwich demonstrated a promising ability to regulate ECs and SMCs with excellent hemocompatibility. 


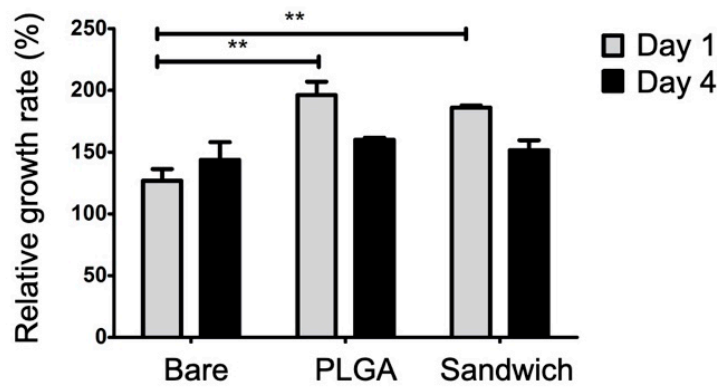

(a)

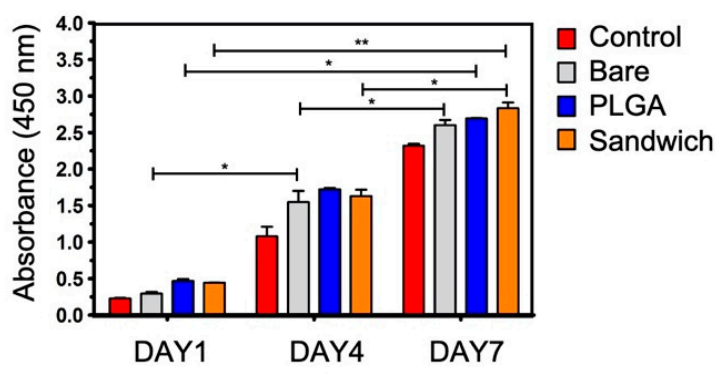

(c)

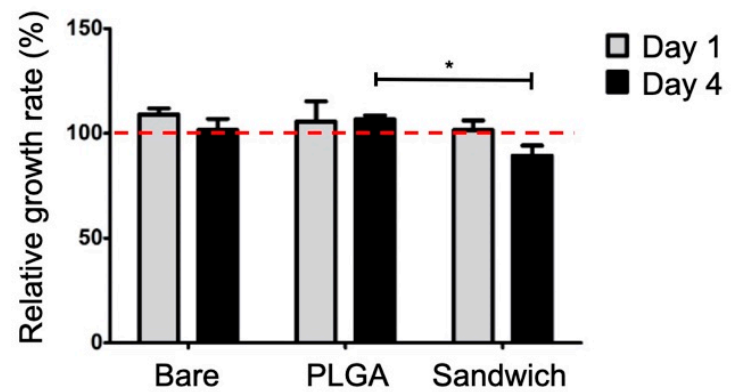

(b)

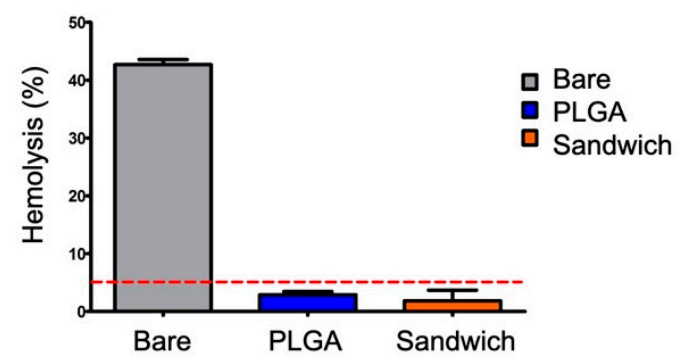

(d)

Figure 6. The cell viability evaluation of (a) ECs and (b) SMCs on day 1, day 4, (c) coatings versus EC proliferation $\left({ }^{*} p<0.05\right.$ and ${ }^{* *} p<0.01$, mean $\pm \mathrm{SD}, \mathrm{N}=3$ ) and (d) the hemolysis test.

\subsection{Anti-Oxidation}

The linear regression retrieved from a gradient GA content test defined a standard reference of GA released weight and concentration (Figure 7a). The sandwich coating film triggered GA weight release at $1,2,3$, and $6 \mathrm{~h}$, with a reduced speed after three hours (Figure $7 \mathrm{~b}$ ). The free radical scavenging analysis showed that the bare, PLGA, and sandwich coatings could eliminate oxidant stress with antioxidant capacities of approximately $28 \%, 36 \%$, and $63 \%$, respectively. These data verified that the GA released from the sandwich coating film promoted scavenging of free radicals and protected the vascular tissue due to its significant anti-oxidative ability, suggesting that the sandwich coating is a promising material for vascular stents (Figure 7c).

\subsection{Cell Migration}

The sandwiched-layer structure ensured that the GA had an anti-proliferative effect on the SMCs and a slight influence on EC migration (Figure 8). Re-endothelialization at the lesion site is a particularly important standard after PCI and requires healthy EC proliferation, migration, and spreading. Additionally, ideal regulation of SMCs and ECs could prevent penetration from SMCs as well as late-stent restenosis. As the previous viability results showed, GA has a specific sensitivity to SMCs and ECs at GA-1wt.\% $(\sim 4 \mu \mathrm{g} / \mathrm{mL})$ in the sandwich-structured film. The results indicated a robust EC migration without a significant difference in migration length among all groups (Figure $8 a$ ). In contrast, the SMCs had a larger migration distance in the PLGA group than in the other groups, while the sandwich and control groups were alike (Figure $8 b$ ). 


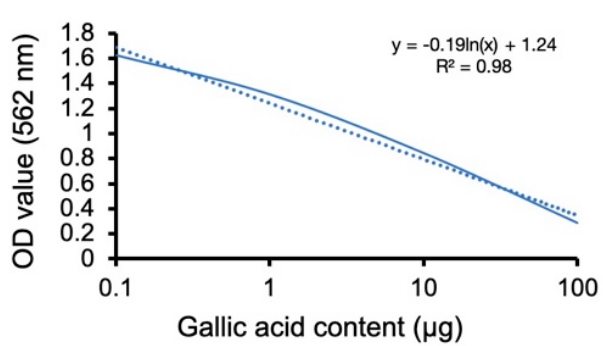

(a)

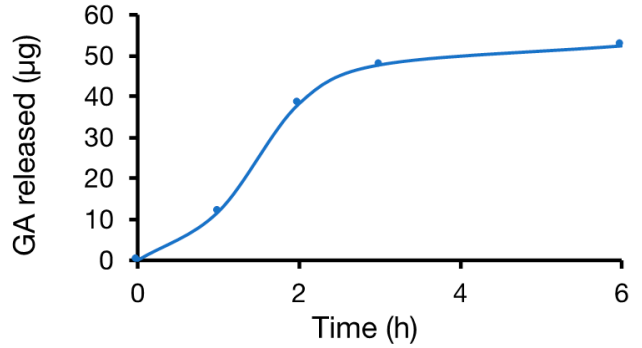

(b)

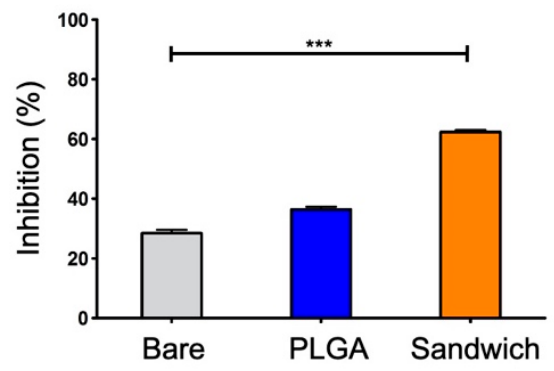

(c)

Figure 7. The anti-oxidation analysis of (a) the DPPH/GA efficiency curve, (b) the sandwich coating film release GA curve and (c) free radical scavenging activity (*** $p<0.001$, mean $\pm \mathrm{SD}, \mathrm{N}=6$ ).

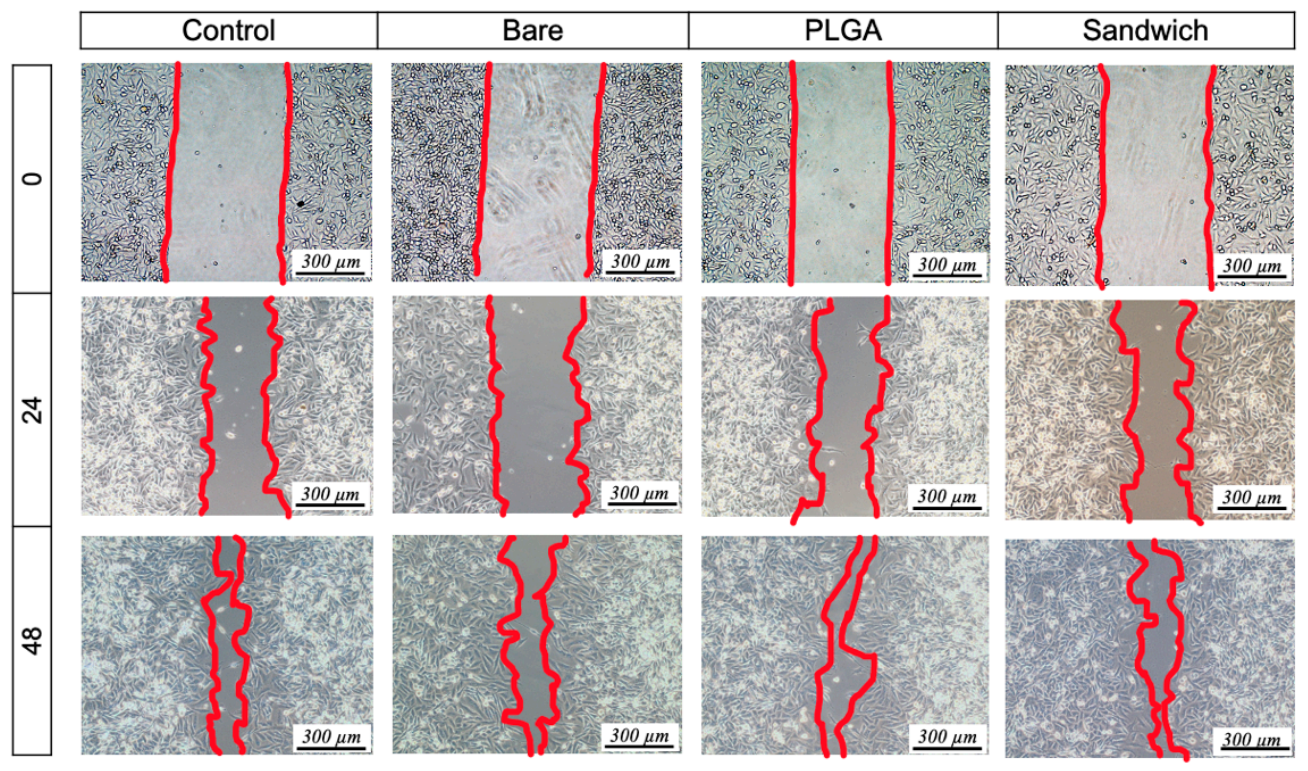

(a)

Figure 8. Cont. 


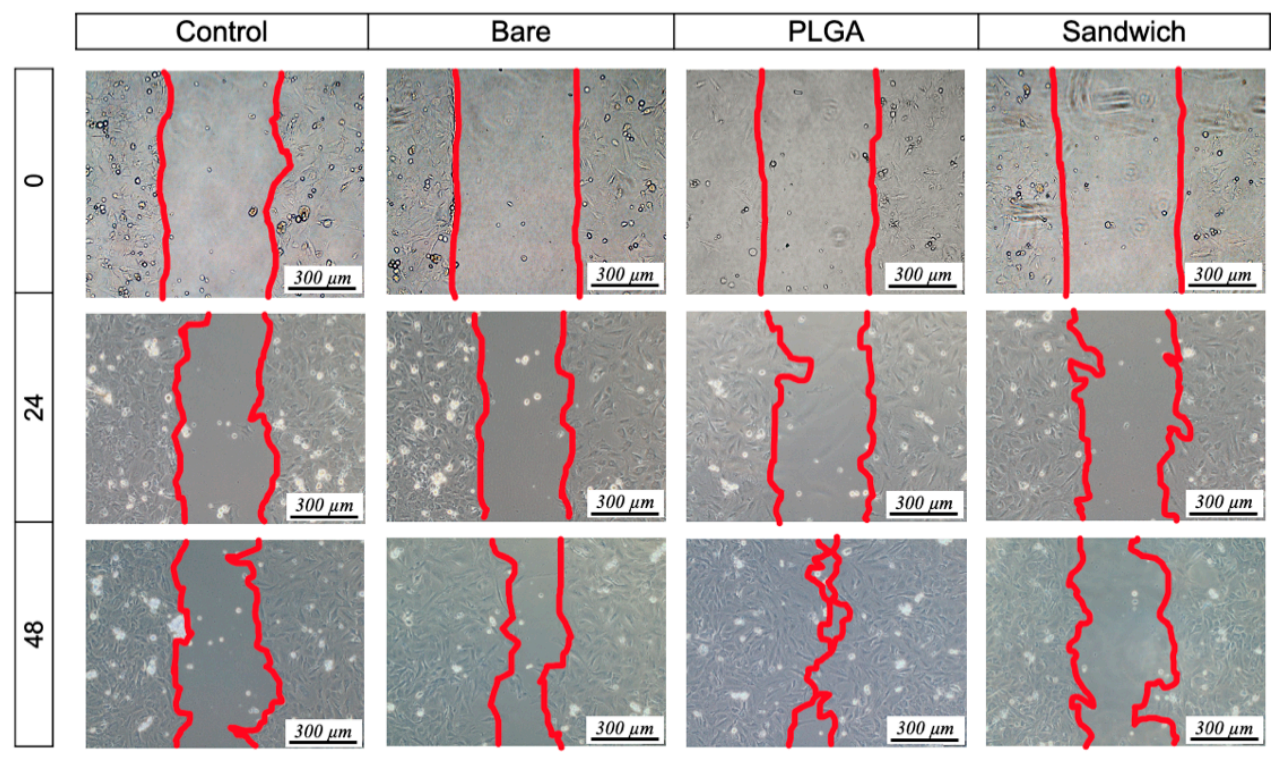

(b)

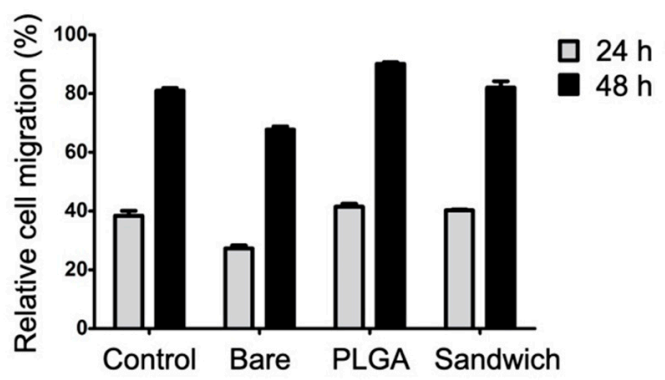

(c)

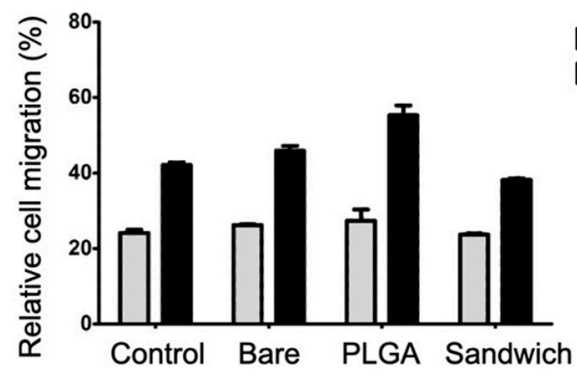

(d)

Figure 8. Cell migration of (a) EC, (b) SMC at 0, 24, and $48 \mathrm{~h}$, and the fitting results for (c) EC and (d) SMC migration coverage (mean $\pm \mathrm{SEM}, \mathrm{N}=3$ ).

An overall analysis of the ECs and SMCs after $48 \mathrm{~h}$ showed $81 \%$ and $42 \%$ migration from sides to the middle wound closure, respectively, in the control group. In the PLGA group, both the ECs and SMCs exhibited migration of $90 \%$ and $55 \%$, respectively (Figure $8 \mathrm{c}, \mathrm{d}$ ). In the bare group, the ECs exhibited mild movement of $68 \%$, and the SMCs showed no significant difference. Furthermore, the sandwich coating, similarly to the control group, displayed migration rates of $82 \%$ for ECs and $38 \%$ for SMCs. The results were consistent with the cytocompatibility test, indicating that sandwich coating preserved the viability of ECs and inhibited the SMCs with the release of GA.

\section{Discussion}

One of the goals of surface modification of ZK60 is to enhance its corrosion resistance in simulated body fluid and hence improve its potential for use in fabricating bioresorbable coronary artery stents. $\mathrm{Mg}(\mathrm{OH})_{2}$ forms a passive layer on the magnesium surface through AHT [36]. This process protects the $\mathrm{Mg}$ surface from ion attack and prevents the accelerated degradation of ZK60 magnesium, which is supported by the polarization test in Figure A2. Based on the limitations in our lab, discussing the LA:GA ratio of PLGA and the coating techniques was beyond the scope of the study. A comprehensive degradation study on PLGA (50:50) and (85:15) revealed that complete degradation of the PLGA (50:50) occurred after 102 days, whereas only about $60 \%$ of the PLGA $(85: 15)$ degraded within the same period [37]. Therefore, we simply discuss the weight percentage of PLGA (based on the 85:15 ratio) for its long-term degradation process and chose the best group as the control group in this study. 
An oxide-passive layer on the Mg-disk led to a coarse surface until the second PLGA layer was deposited on it to fill the cracks (Figure 2), yet this passive layer prevented the initial hydrogen evolution from the ZK60 surface and prevented the acid degradation products of the PLGA layer from penetrating directly into the ZK60 substrate. This phenomenon explains why the $\mathrm{NaOH}$ passive layer is vital to make PLGA layer more completed and concrete on the coated surface. Although dip-coating might not be ideal for stent coating due to the complicated geometry, this technique can be simply conducted and qualifies for further bench testing, such as cytocompatibility and immersion test.

Many studies have investigated the use of phenolic molecules to regulate endothelialization based on their specific properties on SMCs and ECs $[28,29]$. These applications not only prevent the over-growth of SMCs from invading the EC wall but also assist in the formation of a uniform endothelial layer in the vascular system. Further, the goal of drug elution changed from anti-immunity to anti-proliferation since sirolimus (SR) replaced paclitaxel (PTX) as the main drug system for drug-eluting stent [38]. We believe our sandwiched GA concept can bring a novel direction to apply small-molecule on eluting stent instead of traditional SR or PTX. In this paper, the healing process can be nearly completed in $48 \mathrm{~h}$, so a four-day viability test is consistent with the endothelial cell healing process (Figures 6 and 8). Endothelial cells are unique in their growth pattern, preferring to grow in flat structures, so the extreme growth rate without an appropriate dynamic environment, a laminar blood flow, tends to cause apoptosis in limited living space [39,40]. Nevertheless, the opposite behavior between ECs and SMCs in this study suggests that the PLGA films promoted the proliferation of SMCs, while sandwich coating notably delayed them with similar behavior to that of the control group. Many recent clinical trials have revealed that polymer-based stents [18] do not mitigate late-stent restenosis, the SMC migration results may explain the deficiencies related to the use of polymers and offer a possible solution.

The anti-inflammatory effect is another concern related to cardiovascular stents. Phenolic molecules exhibit extraordinary, inherent anti-oxidative abilities, thus helping to scavenge reactive oxygen species and protect vascular tissue. In addition, free radical scavenging decreases oxidants and inhibits the atherogenesis initiated by oxidation of LDL. These antioxidant mechanisms prevent late myocardial infarction and in-stent restenosis after PCI. Although the drug delivery strategy is beyond the scope of our study, the interaction of free-radical capture and the GA delivery trend are what we are interested in. Recently, a free radical scavenging analysis completed by DPPH was conducted to evaluate the antioxidant capacity of the stent platform [34]. Phenolic molecules, such as ECGC and TA [28-31], have been discussed in similar studies, yet the GA application under PLGA eluting stents has not been sufficiently investigated. In our previous study, a phenolic-modified ceramic coating on ZK60 was proven to be efficient on osteo-like cell activity [12]. Due to its ability to capture free radicals and cell selectivity, GA can potentially be applied in the modified polymer coating. However, the GA content is hard to characterize in the host because of the circulation system, which is also correlated to the cell tolerance and apoptosis occurring in a static environment.

Under the limitations of a coating strategy for the complicated geometry of stents and the in vivo environment, only the surface modification and the interaction of materials and cells can be discussed within our scope. To optimize the scale of this research, other coating techniques, such as spray coating, and the in vivo environment will be discussed in the near future.

\section{Conclusions}

PLGA dip-coatings with gallic acid (GA) were prepared on a ZK60 surface in a sandwiched-layer structure. The a close-packed sandwiched layer showed enhanced corrosion resistance and a homogeneous film surface. An in vitro assay demonstrated that the sandwich coating behaved selectively with bioactivity on ECs, significant suppression of SMC over-proliferation, anti-hemolysis ability, and anti-oxidation effects compared to PLGA. This simple technique with a sandwiched-layer structure is a promising surface treatment for a commercialized stent platform for treating atherosclerosis and preventing late-stent restenosis. 
Author Contributions: Conceptualization, L.-H.L. and H.-P.L.; methodology, L.-H.L.; software, L.-H.L.; validation, L.-H.L.; formal analysis, L.-H.L.; investigation, L.-H.L.; resources, L.-H.L.; data curation, L.-H.L.; writing-original draft preparation, L.-H.L.; writing—review and editing, H.-P.L. and M.-L.Y.; visualization, L.-H.L. and H.-P.L.; supervision, M.-L.Y.; project administration, M.-L.Y.; funding acquisition, M.-L.Y. All authors have read and agreed to the published version of the manuscript.

Funding: This research was financially supported by Ministry of Science and Technology in Taiwan through Grants MOST-106-3114-E-006-012 and Medical Device Innovation Center (MDIC), National Cheng Kung University (NCKU) from the Featured Areas Research Center Program within the framework of the Higher Education Sprout Project by the Ministry of Education (MoE) in Taiwan.

Acknowledgments: This research was supported by the Nano Biomedical and Tissue Engineering LAB, Department of BME, National Cheng Kung University. We thank INTAI Technology and CHONG HUAI Laser for providing the Laser technique of Mg-stents.

Conflicts of Interest: The authors declare no conflict of interest. The funders had no role in the design of the study; in the collection, analyses, or interpretation of data; in the writing of the manuscript, or in the decision to publish the results.

\section{Appendix A}

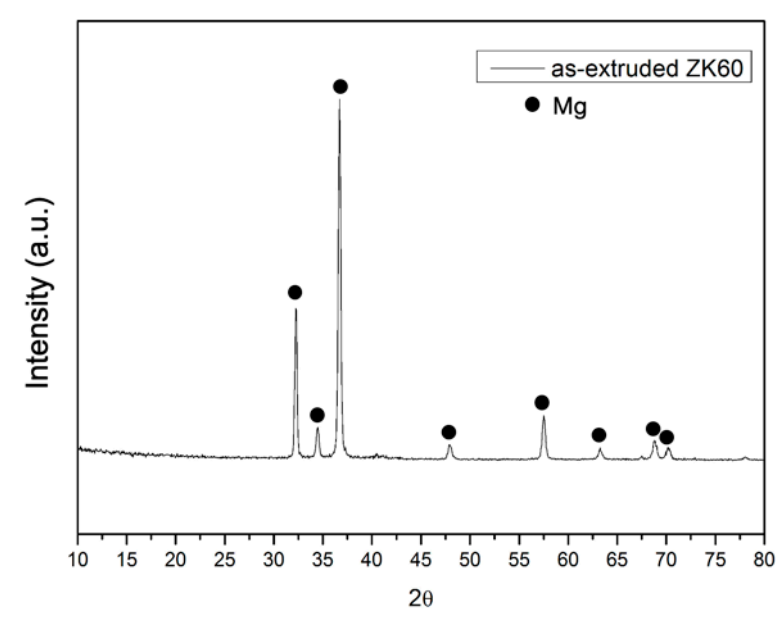

Figure A1. XRD patterns of as-extruded ZK60.
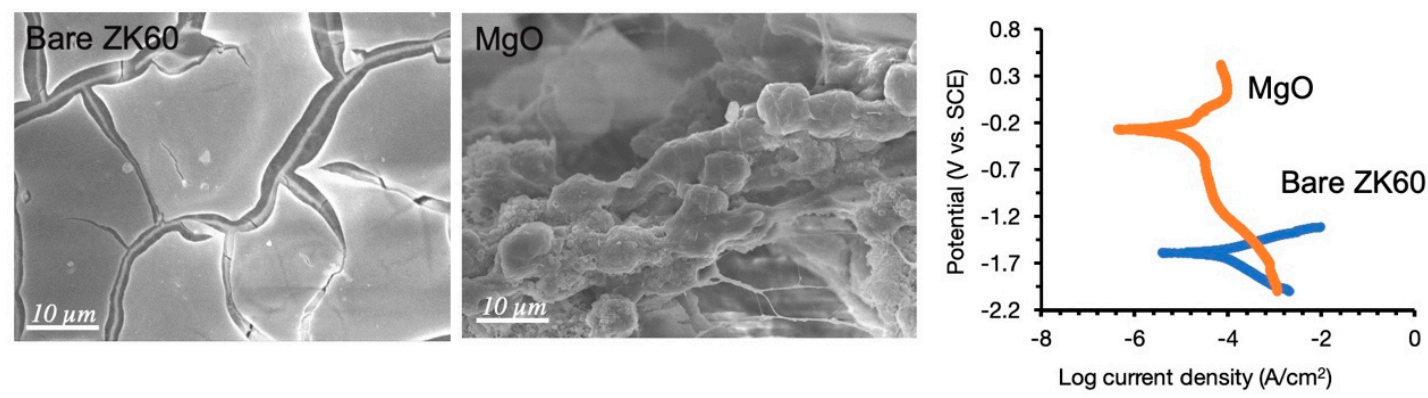

Figure A2. The MG63 attachment morphology of bare ZK60 and MgO and the potentiodynamic polarization curves of bare ZK60 and $\mathrm{MgO}$. 


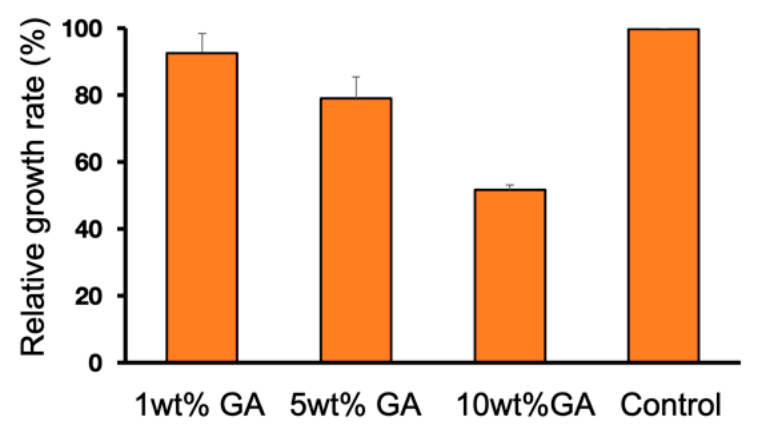

Figure A3. The cytocompatibility evaluation of GA content versus the relative growth rate (mean $\pm \mathrm{SD}$, $\mathrm{N}=3$ )

\section{References}

1. Letchumanan, I.; Arshad, M.M.; Gopinath, S.C. Nanodiagnostic Attainments and Clinical Perspectives on C-Reactive Protein: Cardiovascular Disease Risks Assessment. Curr. Med. Chem. 2020, 27, 1. [CrossRef]

2. Stone, G.W.; Aronow, H.D. Long-term Care After Percutaneous Coronary Intervention: Focus on the Role of Antiplatelet Therapy. Mayo Clin. Proc. 2006, 81, 641-652. [CrossRef] [PubMed]

3. Hanawa, T. Materials for metallic stents. J. Artif. Organs 2009, 12, 73-79. [CrossRef] [PubMed]

4. Moravej, M.; Mantovani, D. Biodegradable Metals for Cardiovascular Stent Application: Interests and New Opportunities. Int. J. Mol. Sci. 2011, 12, 4250-4270. [CrossRef] [PubMed]

5. Waksman, R.; Pakala, R.; Eric, W.; Hartwig, S.; Harder, C.; Rohde, R.; Heublein, B.; Alex, H.; Andreae, A.; Waldman, K.H. Effect of magnesium alloy stents in porcine coronary arteries: Morphometric analysis of a long-term study. J. Am. Coll. Cardiol. 2006, 47, 23B.

6. Shi, Y.; Pei, J.; Zhang, L.; Lee, B.-K.; Yun, Y.; Zhang, J.; Li, Z.; Gu, S.; Park, K.; Yuan, G. Understanding the effect of magnesium degradation on drug release and anti-proliferation on smooth muscle cells for magnesium-based drug eluting stents. Corros. Sci. 2017, 123, 297-309. [CrossRef]

7. Ang, H.Y.; Huang, Y.Y.; Lim, S.T.; Wong, P.; Joner, M.; Foin, N. Mechanical behavior of polymer-based vs. metallic-based bioresorbable stents. J. Thorac. Dis. 2017, 9, S923-S934. [CrossRef]

8. Li, Y.; Wang, L.; Chen, S.; Yu, D.; Sun, W.; Xin, S. Biodegradable Magnesium Alloy Stents as a Treatment for Vein Graft Restenosis. Yonsei Med. J. 2019, 60, 429-439. [CrossRef]

9. Barkholt, T.Ø.; Webber, B.; Holm, N.R.; Ormiston, J.A. Mechanical properties of the drug-eluting bioresorbable magnesium scaffold compared with polymeric scaffolds and a permanent metallic drug-eluting stent. Catheter. Cardiovasc. Interv. 2019. Available online: https://onlinelibrary.wiley.com/doi/full/10.1002/ccd.28545 (accessed on 11 November 2019). [CrossRef]

10. Kang, M.-H.; Jang, T.-S.; Kim, S.W.; Park, H.-S.; Song, J.; Kim, H.-E.; Jung, K.-H.; Jung, H.-D. MgF2-coated porous magnesium/alumina scaffolds with improved strength, corrosion resistance, and biological performance for biomedical applications. Mater. Sci. Eng. C 2016, 62, 634-642. [CrossRef]

11. Kim, S.-Y.; Kim, Y.K.; Ryu, M.-H.; Bae, T.-S.; Lee, M.-H. Corrosion resistance and bioactivity enhancement of MAO coated Mg alloy depending on the time of hydrothermal treatment in Ca-EDTA solution. Sci. Rep. 2017, 7, 1-11. [CrossRef] [PubMed]

12. Lee, H.-P.; Lin, D.-J.; Yeh, M.-L. Phenolic Modified Ceramic Coating on Biodegradable Mg Alloy: The Improved Corrosion Resistance and Osteoblast-Like Cell Activity. Mater. 2017, 10, 696. [CrossRef] [PubMed]

13. Lin, D.-J.; Hung, F.-Y.; Jakfar, S.; Yeh, M.-L. Tailored coating chemistry and interfacial properties for construction of bioactive ceramic coatings on magnesium biomaterial. Mater. Des. 2016, 89, 235-244. [CrossRef]

14. Lin, D.-J.; Hung, F.-Y.; Yeh, M.-L.; Lee, H.-P.; Lui, T.-S. Development of a novel micro-textured surface using duplex surface modification for biomedical Mg alloy applications. Mater. Lett. 2017, 206, 9-12. [CrossRef]

15. Lin, X.; Tan, L.; Wang, Q.; Zhang, G.; Zhang, B.; Yang, K. In vivo degradation and tissue compatibility of ZK60 magnesium alloy with micro-arc oxidation coating in a transcortical model. Mater. Sci. Eng. C 2013, 33, 3881-3888. [CrossRef] 
16. Makkar, P.; Kang, H.J.; Padalhin, A.R.; Park, I.; Moon, B.-G.; Lee, B.T. Development and properties of duplex MgF2/PCL coatings on biodegradable magnesium alloy for biomedical applications. PLoS ONE 2018, 13, e0193927. [CrossRef]

17. Jiang, W.; Tian, Q.; Vuong, T.; Shashaty, M.; Gopez, C.; Sanders, T.; Liu, H. Comparison Study on Four Biodegradable Polymer Coatings for Controlling Magnesium Degradation and Human Endothelial Cell Adhesion and Spreading. ACS Biomater. Sci. Eng. 2017, 3, 936-950. [CrossRef]

18. Strohbach, A.; Busch, R. Polymers for Cardiovascular Stent Coatings. Int. J. Polym. Sci. 2015, 2015, 1-11. [CrossRef]

19. Lakalayeh, G.A.; Rahvar, M.; Haririan, E.; Karimi, R.; Ghanbari, H. Comparative study of different polymeric coatings for the next-generation magnesium-based biodegradable stents. Artif. Cells Nanomed. Biotechnol. 2017, 46, 1380-1389. [CrossRef]

20. Garcia-Garcia, H.M.; Wopperer, S.; Seleme, V.B.; Ribeiro, M.H.; Campos, C.M. The Development of Magnesium-Based Resorbable and Iron-Based Biocorrodible Metal Scaffold Technology and Biomedical Applications in Coronary Artery Disease Patients. Appl. Sci. 2019, 9, 3527.

21. He, Y.; Wang, J.; Yan, W.; Huang, N. Gallic acid and gallic acid-loaded coating involved in selective regulation of platelet, endothelial and smooth muscle cell fate. RSC Adv. 2014, 4, 212-221. [CrossRef]

22. Yang, Z.; Xiong, K.; Qi, P.; Yang, Y.; Tu, Q.; Wang, J.; Huang, N. Gallic Acid Tailoring Surface Functionalities of Plasma-Polymerized Allylamine-Coated 316L SS to Selectively Direct Vascular Endothelial and Smooth Muscle Cell Fate for Enhanced Endothelialization. ACS Appl. Mater. Interfaces 2014, 6, 2647-2656. [CrossRef] [PubMed]

23. Badhani, B.; Sharma, N.; Kakkar, R. Gallic acid: A versatile antioxidant with promising therapeutic and industrial applications. RSC Adv. 2015, 5, 27540-27557. [CrossRef]

24. Lim, K.S.; Park, J.-K.; Jeong, J.-O.; Bae, I.H.; Park, D.S.; Shim, J.W.; Kim, J.H.; Kim, H.K.; Kim, S.S.; Sim, O.S.; et al. Anti-Inflammatory Effect of Gallic Acid-Eluting Stent in a Porcine Coronary Restenosis Model. Acta Cardiol. Sin. 2018, 34, 224-232.

25. Diaz, M.N.; Frei, B.; Vita, J.A.; Keaney, J.F. Antioxidants and Atherosclerotic Heart Disease. N. Engl. J. Med. 1997, 337, 408-416. [CrossRef]

26. Zhang, H.; Luo, R.; Li, W.; Wang, J.; Maitz, M.F.; Wang, J.; Wan, G.; Chen, Y.; Sun, H.; Jiang, C.; et al. Epigallocatechin gallate (EGCG) induced chemical conversion coatings for corrosion protection of biomedical MgZnMn alloys. Corros. Sci. 2015, 94, 305-315. [CrossRef]

27. Zhang, B.; Yao, R.; Li, L.; Li, M.; Yang, L.; Liang, Z.; Yu, H.; Zhang, H.; Luo, R.; Wang, Y. Bionic Tea Stain-Like, All-Nanoparticle Coating for Biocompatible Corrosion Protection. Adv. Mater. Interfaces 2019, 6, 1900899. [CrossRef]

28. Zhang, B.; Yao, R.; Li, L.; Wang, Y.; Luo, R.; Yang, L.; Wang, Y. Green Tea Polyphenol Induced Mg2+-rich Multilayer Conversion Coating: Toward Enhanced Corrosion Resistance and Promoted in Situ Endothelialization of AZ31 for Potential Cardiovascular Applications. ACS Appl. Mater. Interfaces 2019, 11, 41165-41177. [CrossRef]

29. Chen, S.; Zhao, S.; Chen, M.; Zhang, X.; Zhang, J.; Li, X.; Zhang, H.; Shen, X.; Wang, J.; Huang, N. The anticorrosion mechanism of phenolic conversion coating applied on magnesium implants. Appl. Surf. Sci. 2019, 463, 953-967. [CrossRef]

30. Cipriano, A.F.; Sallee, A.; Tayoba, M.; Alcaraz, M.C.C.; Lin, A.; Guan, R.-G.; Zhao, Z.-Y.; Liu, H. Cytocompatibility and early inflammatory response of human endothelial cells in direct culture with Mg-Zn-Sr alloys. Acta Biomater. 2017, 48, 499-520. [CrossRef]

31. Lin, D.-J.; Hung, F.-Y.; Liu, H.-J.; Yeh, M.-L. Dynamic Corrosion and Material Characteristics of Mg-Zn-Zr Mini-Tubes: The Influence of Microstructures and Extrusion Parameters. Adv. Eng. Mater. 2017, 19, 1700159. [CrossRef]

32. Lin, D.-J.; Hung, F.-Y.; Yeh, M.-L.; Lui, T.-S. Microstructure-modified biodegradable magnesium alloy for promoting cytocompatibility and wound healing in vitro. J. Mater. Sci. Mater. Electron. 2015, 26, 1-10. [CrossRef] [PubMed]

33. Uan, J.-Y.; Yu, S.-H.; Lin, M.-C.; Chen, L.-F.; Lin, H.-I. Evolution of hydrogen from magnesium alloy scraps in citric acid-added seawater without catalyst. Int. J. Hydrogen Energy 2009, 34, 6137-6142. [CrossRef]

34. Seyfert, U.T.; Biehl, V.; Schenk, J. In vitro hemocompatibility testing of biomaterials according to the ISO 10993-4. Biomol. Eng. 2002, 19, 91-96. [CrossRef] 
35. Garcia, E.J.; Oldoni, T.L.C.; De Alencar, S.M.; Reis, A.; Loguercio, A.D.; Grande, R.H.M. Antioxidant activity by DPPH assay of potential solutions to be applied on bleached teeth. Braz. Dent. J. 2012, 23, $22-27$. [CrossRef] [PubMed]

36. Hirun, N.; Dokmaisrijan, S.; Tantishaiyakul, V. Experimental FTIR and theoretical studies of gallic acid-acetonitrile clusters. Spectrochim. Acta Part A Mol. Biomol. Spectrosc. 2012, 86, 93-100. [CrossRef]

37. Li, L.; Gao, J.; Wang, Y. Evaluation of cyto-toxicity and corrosion behavior of alkali-heat-treated magnesium in simulated body fluid. Surf. Coat. Technol. 2004, 185, 92-98. [CrossRef]

38. Hussein, A.S.; Ahmadun, F.-R.; Abdullah, N. In vitro degradation of poly (D, L-lactide-co-glycolide) nanoparticles loaded with linamarin. IET Nanobiotechnol. 2013, 7, 33-41. [CrossRef]

39. Htay, T.; Liu, M.W. Drug-eluting stent: a review and update. Vasc. Heal. Risk Manag. 2005, 1, $263-276$. [CrossRef]

40. Ye, C.; Wang, J.; Zhao, A.; He, D.; Maitz, M.F.; Zhou, N.; Huang, N. Atorvastatin Eluting Coating for Magnesium-Based Stents: Control of Degradation and Endothelialization in a Microfluidic Assay and In Vivo. Adv. Mater. Technol. 2020, 5, 1900947. [CrossRef]

Publisher's Note: MDPI stays neutral with regard to jurisdictional claims in published maps and institutional affiliations.

(C) 2020 by the authors. Licensee MDPI, Basel, Switzerland. This article is an open access article distributed under the terms and conditions of the Creative Commons Attribution (CC BY) license (http://creativecommons.org/licenses/by/4.0/). 